Abstract-To explore the feasibility of using beak microstructure to estimate the age of oceanic squid, sagittal sections in the upper beak were used to validate the age of the red flying squid (Ommastrephes bartramii) in the North Pacific Ocean. The growth rates of mantle length (ML) and body weight (BW) were estimated on the basis of beak increments. We compared growth curves derived from previous statolith-based studies and those from this study. Results indicate that the mean age of females and males was 203 d (standard deviation [SD] 55) and 180 $\mathrm{d}$ (SD 45). The hatching period occurred during October-June of the following year, and hatching peaked during January-April on the basis of back-calculation. All sampled squid belonged to the winter-spring cohort. Females and males had a similar growth pattern in ML and BW with increased ages, except for male ML after age 301-350 d. An exponential model best described the relationships between age and ML as well as BW for both sexes. The difference in growth curves and lower growth rates reported here, compared with those of previous studies, may result from different stock structures and extreme weather. This study confirmed that beak length works well for estimating the age of oceanic squid.

Manuscript submitted 18 February 2015 Manuscript accepted 19 October 2015. Fish. Bull. 114:34-44 (2016).

Online publication date: 5 November 2015 . doi. 10.7755/FB.114.1.3

The views and opinions expressed or implied in this article are those of the author (or authors) and do not necessarily reflect the position of the National Marine Fisheries Service, NOAA.

\title{
Age, growth, and population structure of the red flying squid (Ommastrephes bartramin) in the North Pacific Ocean, determined from beak microstructure
}

\author{
Zhou Fang 1,5,4 \\ Xinjun Chen (contact author) 1,2,3,5 \\ Jianhua $\mathrm{Li}^{1,2,3,5}$ \\ Bilin Liu 1,2,3,5 \\ Katherine Thompson 4 \\ Yong Chen ${ }^{4,5}$ \\ Feifei $\mathrm{Hu}^{1}$ \\ Email address for contact author: xjchen@shou.edu.cn \\ ${ }^{1}$ College of Marine Sciences \\ Shanghai Ocean University \\ 999 Hucheng Ring Road \\ Shanghai 201306, China \\ 2 National Engineering Research Center for \\ Oceanic Fisheries \\ Shanghai Ocean University \\ 999 Hucheng Ring Road \\ Shanghai 201306, China \\ ${ }^{3}$ Key Laboratory of Sustainable Exploitation \\ of Oceanic Fisheries Resources \\ Ministry of Education \\ Shanghai Ocean University \\ 999 Hucheng Ring Road \\ Shanghai 201306, China \\ 4 School of Marine Sciences \\ 218 Libby Hall \\ University of Maine \\ Orono, Maine 04469 \\ ${ }^{5}$ Collaborative Innovation Center for Distant- \\ water Fisheries \\ 999 Hucheng Ring Road \\ Shanghai 201306, China
}

The red flying squid (Ommastrephes bartramii) is distributed in subtropical and temperate waters worldwide but is commercially exploited only in the North Pacific Ocean, where it plays an important role in the marine ecosystem (Jereb and Roper, 2010; Navarro et al., 2013). It has become a primary target species in East Asian countries since the oceanic squid fishery began in the 1970s. This squid is not only important as a fishery resource but also serves as an indicator of large-scale oceanographic changes (Chen et al., 2007; Nishikawa et al., 2014). The population of red flying squid in the North Pacific Ocean consists of 2 main cohorts, the autumn cohort that yields large squid (>350 mm mantle length [ML]) and the winter-spring cohort that is represented by relatively small squid
(<350 mm ML) (Chen and Chiu, 2003). Abundance of both cohorts fluctuates greatly with large-scale oceanographic and climatic changes (e.g., El Ninõ or La Ninã), as well as with regional-scale environmental changes (Yatsu et al., 2000; Chen et al., 2007).

Age estimation and growth analyses provide critical information for fisheries stock assessments and management. Hard structures often are used for aging squid and most studies measure statoliths (Spratt, 1978; Lipinski, 1986; Jackson et al., 1993; Durholtz et al., 2002). Although statolith-based age determination methods have advanced greatly over the past 30 years (Arkhipkin and Shcherbich, 2012), the process of preparing statoliths for aging is rather complicated and often has a 
relatively low success rate. Potential use of alternative methods has been the topic of recent discussions (Moltschaniwskyj and Cappo, 2009). For example, the beak, which is the main feeding organ for squids, has a stable morphological structure because of its chitinous structure (Clarke, 1986) and could potentially be used for determination of a squid's age. Removing a whole beak from the buccal mass is much easier than extracting a statolith from the statocyst. The beak, therefore, has been identified as an appropriate structure for studies of squid biology and ecology (Jackson et al., 1997; Gröger et al., 2000; Martínez et al., 2002; Cherel and Hobson, 2005; Guerra et al., 2010).

Clarke (1965) first identified the incremental structure in the beak of Moroteuthis ingens and demonstrated its potential for estimating age. Raya and Hernández-González (1998) suggested the sagittal plane of a rostrum sagittal section (RSS) as the optimal plane for aging common octopus (Octopus vulgaris), and longitudinal increments deposited in RSS were also observed to have periodic light and dark bands. The lateral wall surface (LWS) of the beak also can be used for reading growth increments, and a study over a specific period indicated that one ring represents $1 \mathrm{~d}$ of life in postlarvae (Hernández-López et al., 2001). Perales-Raya et al. (2010) improved beak aging methods and compared the precision of readable growth increments between RSS and LWS methods. They found that the RSS yielded more precise age estimates but that the LWS was quicker and simpler to prepare (Perales-Raya et al., 2010). Canali et al. (2011) and Castanhari and Tomás (2012) also analyzed the upper beak microstructure and the relationship between increments and ML or body weight (BW). Examination of the upper beak has been recommended as a simple and effective approach for estimating cephalopod age (Canali et al., 2011; Castanhari and Tomás, 2012).

Previous studies on squid growth have focused primarily on seasonal and population variability in body size (Chen and Chiu, 2003; Ichii et al., 2004). Variation of oceanographic conditions and feeding habits can greatly impact the growth of red flying squid (Watanabe et al., 2004; Ichii et al., 2009). Oceanic squid tend to migrate over long-distances between their spawning or nursery grounds and their feeding grounds (Semmens et al., 2007). Individuals are exposed to varied environmental conditions during ontogenesis. Therefore, age estimation is an important part of analyzing growth rates for the different life stages of squids. The age-based calculation of growth rates that is based on measurements of statoliths is a popular method and has been used in making growth estimations for oceanic squid. The growth rates of ML and BW for some ommasterphid species have also been derived from statoliths (Markaida et al., 2004; Keyl, 2009; Chen et al., 2011, 2013).

In this study, we used beak microstructure of red flying squid to identify its spawning season and to examine age composition. The relationships between ML, $\mathrm{BW}$, main beak morphometric variables, and age were defined in order to examine squid growth patterns. The relative differences between females and males were also investigated. This study is one of the first in which oceanic ommasterphid squid has been aged by using beak measurements. These methods can be applied to age and growth analyses of other oceanic cephalopods.

\section{Materials and methods}

Squid samples were randomly collected from Chinese commercial jigging vessels FV Jinhai 827 and FV Ningtai 21 in fishing grounds (between $154^{\circ} \mathrm{E}-174^{\circ} \mathrm{W}$ and $39^{\circ} \mathrm{N}-45^{\circ} \mathrm{N}$ ) of the North Pacific Ocean from July through November in 2011 (Fig. 1). Samples were immediately frozen at $-18^{\circ} \mathrm{C}$ for subsequent laboratory work.

After samples were thawed in the laboratory, dorsal ML and BW were measured to the nearest $1 \mathrm{~mm}$ and $1 \mathrm{~g}$, respectively. The upper and lower beaks were then dissected from the buccal mass, washed with fresh water, and stored in a solution of $75 \%$ ethyl alcohol. The following 12 morphological variables were measured to the nearest $0.1 \mathrm{~mm}$ : upper hood length, upper crest length, upper rostrum length (URL), upper rostrum width, upper lateral wall length, upper wing length, lower hood length, lower crest length, lower rostrum length, lower rostrum width, lower lateral wall length, and lower wing length (Fig. 2A; Chen et al., 2012).

For age estimation, the use of RSS has been reported to be more precise than the use of LWS (Perales-Raya et al., 2010). The lower beak is more likely to be subject to erosion because it always covers the upper beak during biting and chewing. Moreover, the rostrum tip of the lower beak also has the function of paralyzing prey organisms (Nixon, 1973). The upper beak has a relatively complete rostrum tip, although erosion may still occur. Therefore, we measured the RSS of the upper beak in this study. The upper beak was cut in half with scissors, producing 2 RSS pieces. To count increments as accurately as possible, we cut the RSS into 2 different sizes and used the larger one, which tended to have a preserved focal plane representing all growth rings in the central section. The larger half of the RSS was cleaned with water to remove mucus and was embedded in a small mold with epoxy resin. We ground the focal plane with 120-, 600-, and 1200-grit waterproof sandpaper until the growth increments became clearly visible. Finally, we polished the RSS slice with 0.05- $\mu \mathrm{m}$ aluminium oxide powder to remove scratches on the surface. This preparation process is similar to that for statoliths (Dawe and Natsukari, 1991).

The number of increments in each RSS were counted with a microscope (Olympus Corp., ${ }^{1}$ Tokyo) at magnifications of $10 \times, 40 \times$, and $400 \times$. Images of different sections were taken with a charge coupled device (CCD)

\footnotetext{
${ }^{1}$ Mention of trade names or commercial companies is for identification purposes only and does not imply endorsement by the authors or the National Marine Fisheries Service, NOAA.
} 


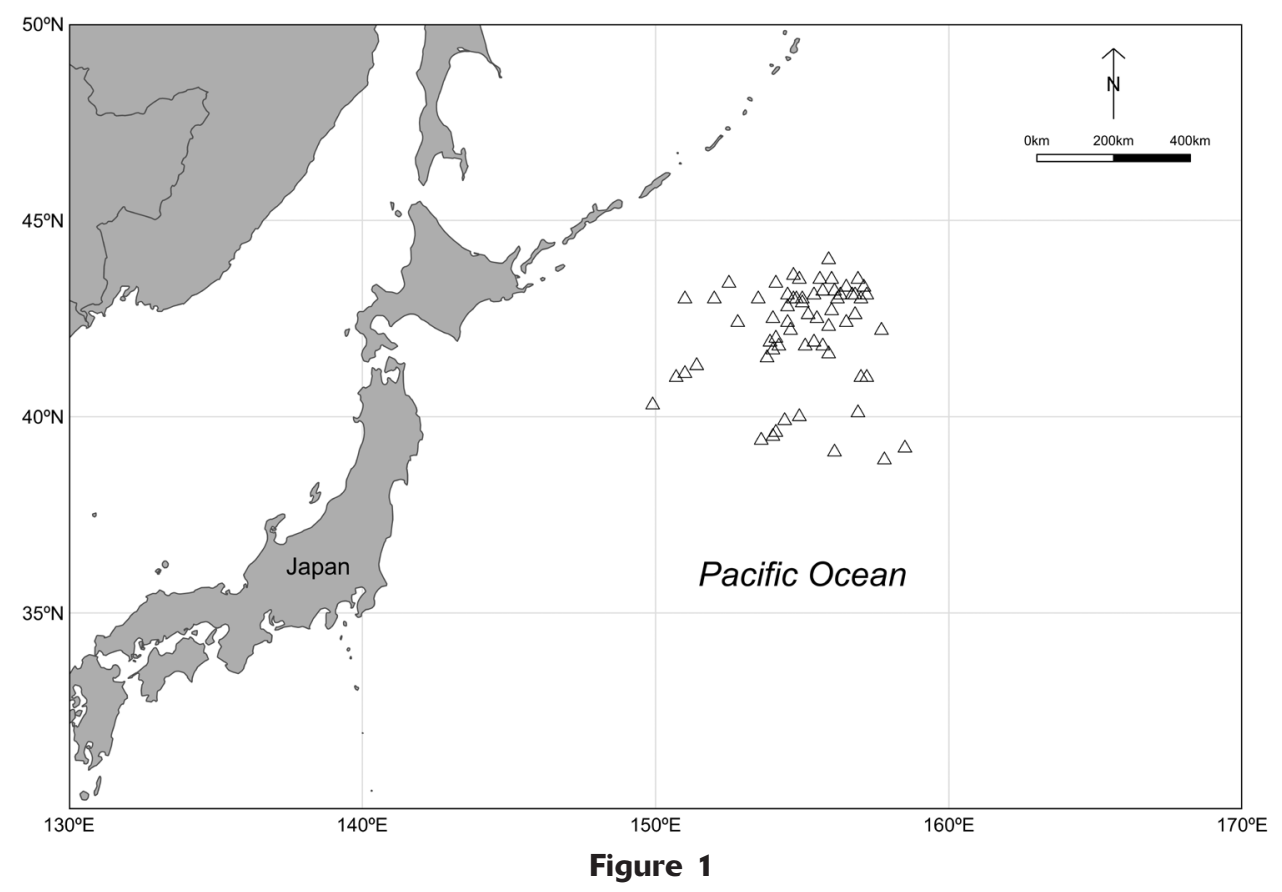

Locations where samples of red flying squid (Ommastrephes bartramii) were collected for this study in the North Pacific Ocean from July through November in 2011.

then processed with Adobe Photoshop CS 5.0 (Adobe Systems Inc., San Jose, CA). Two readers counted the number of increments, and readings were accepted only when the difference in mean counts between the 2 independent readers was less than $10 \%$ (Chen et al., 2013). Beak growth increments in previous studies were assumed to be deposited daily for several octopuses species (Raya and Hernández-González, 1998; Hernández-López et al., 2001; Perales-Raya et al., 2010, 2014; Canali et al., 2011; Castanhari and Tomás, 2012; Rodríguez-Domínguez et al., 2013; Bárcenas et al., 2014). A strict age validation for ommasterphid squids with the use of statolith and beak measurements has been performed and the results of those experiments indicate that the beak is a reliable material for age estimation (Hu et al., 2015; Liu et al., 2015). If the beak is a reliable structure for age estimates, we can back-calculate hatching dates from the capture dates documented in our study.

The relationships between age and $\mathrm{ML}, \mathrm{BW}$, and URL were established with 4 types of curves: linear, power, exponential, and logarithmic. Akaike's information criterion was used to compare the fits of models, by following the calculations of Haddon (2001). Differences in growth curves between sexes also were evaluated by using analysis of covariance (ANCOVA).

Instantaneous growth rate (G) and absolute daily growth rate (DGR) of ML or BW were measured in millimeters per day or grams per day and estimated for each 50-d interval by sex. The G and DGR were calculated with the following models proposed by Forsythe and Van Heukelem (1987): and

$$
G=\frac{\ln \left(S_{2}\right)-\ln \left(S_{2}\right)}{t_{2}-t_{1}} \times 100 \%
$$

$$
D G R=\frac{S_{2}-S_{1}}{t_{2}-t_{1}}
$$

where $S_{1}$ and $S_{2}=$ mean ML or BW at the beginning $\left(t_{1}\right)$ and end $\left(t_{2}\right)$ of the time interval.

Statistical analyses were conducted with SPSS, vers 19.0 (IBM Corp, Armonk, NY).

\section{Results}

\section{Microstructure of growth increments in red flying squid}

The microstructure of a beak RSS of a red flying squid in this study is shown in Figure 2. The longitudinal increments in the transverse surface were easily visible from the tip of rostrum to the joint of the hood and crest (Fig. 2B), and the hood was darker than the crest because of pigmentation (Fig. 2B). The tip of the rostrum was missing in some samples because of erosion from feeding behavior. Increments were more obvious in the center of the focal line and were visible as bands that were alternately dark and light (Fig. 2C). The increments in the middle of each internal rostral axis were much thicker than those in the anterior and posterior areas. The middle parts of the RSS had the widest incremental width in relation to other RSS parts (Fig. 2C). The interval widths tended to vary in different parts of the RSS at increased magnification 


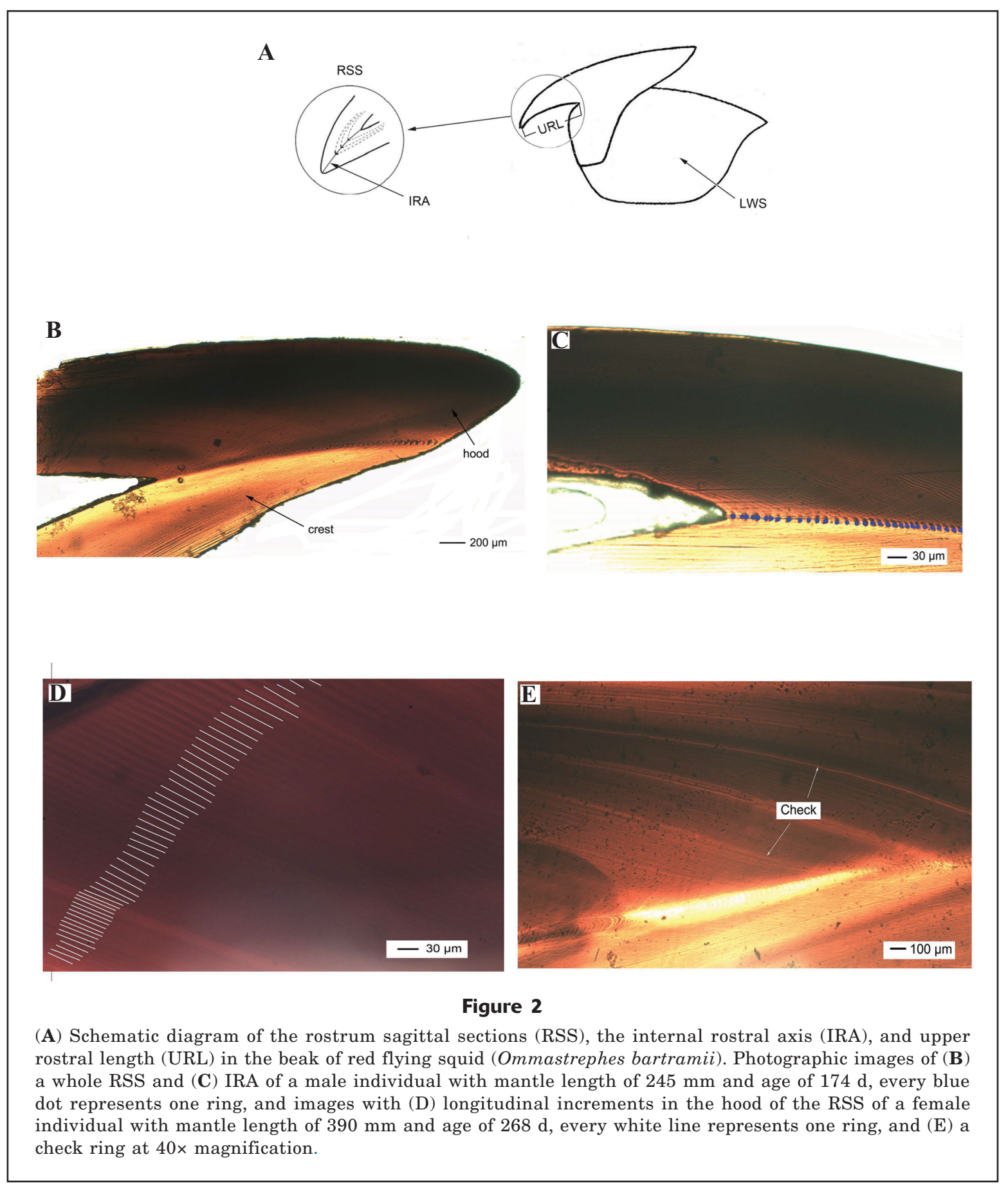

(400x) (Fig. 2D). The mean width of increments in the RSS was $12.6 \mu \mathrm{m}$ (standard deviation [SD] 0.03).

In some atypical beak samples, we found "check" rings, which were similar to the rings in the microstructure of the statolith (Fig. 2E). A check ring was an extremely light band that appeared in multiple increments. These types of increments were easy to discern in comparison with the surrounding regular increments. This structure occurred much more frequently in females than in males.

\section{Age composition and hatching time}

The total sample size was 211 Squid, of which 109 were females and 102 were males. The ML of females ranged from 199 to $417 \mathrm{~mm}$ (average=268 $\mathrm{mm}$ [SD 44]). The majority $(85.4 \%)$ of females ranged from 240 to 320 $\mathrm{mm}$ in ML. Male ML ranged from 201 to $354 \mathrm{~mm}$ (average $=248 \mathrm{~mm}$ [SD 33]); 85.4\% males ranged from 240 to $280 \mathrm{~mm}$ ML (Fig. 3A). Female BW ranged from 140 to $2230 \mathrm{~g}$ (average=603 g [SD 353]); 72.7\% of females 


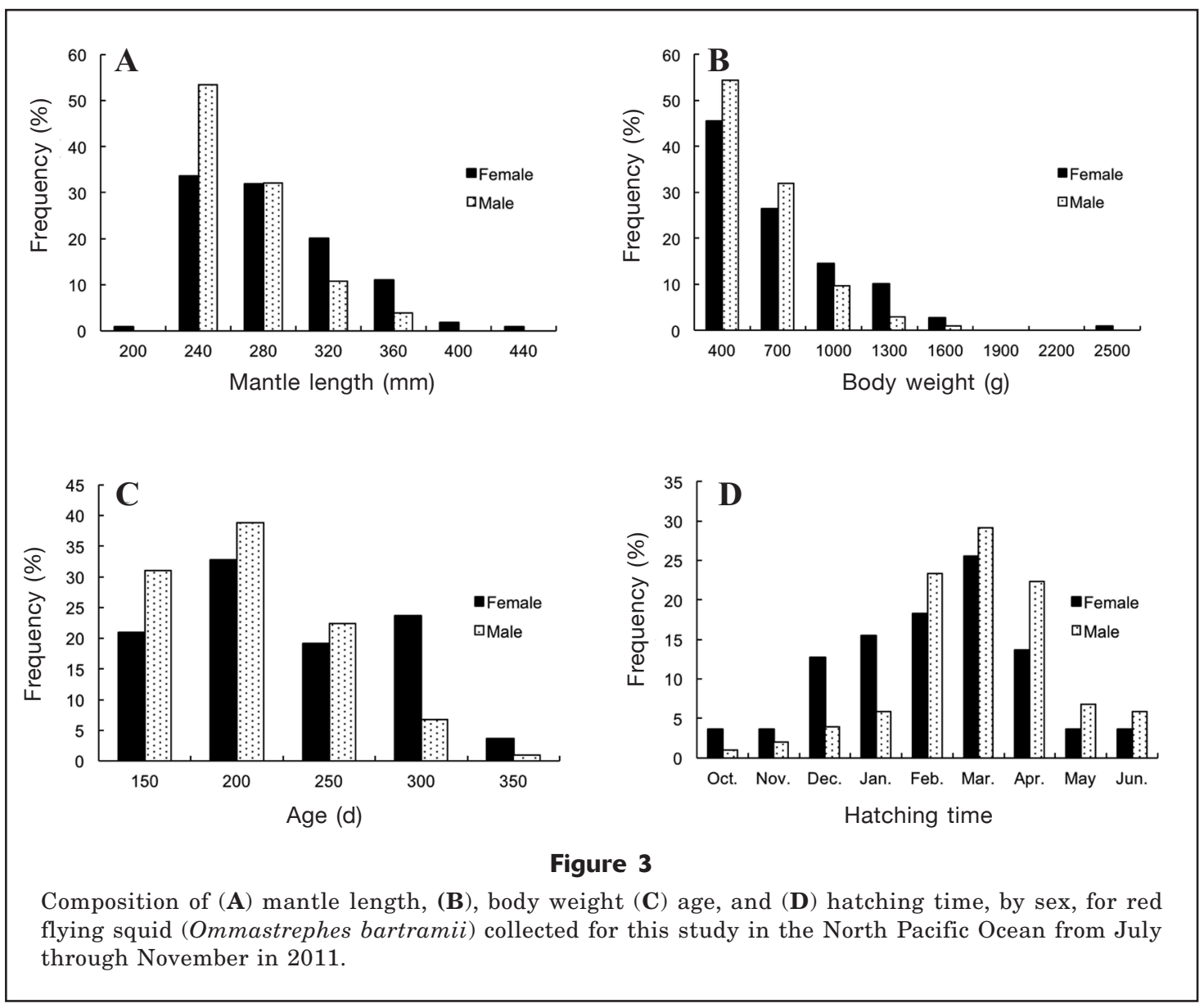

Table 1

Absolute daily growth rates (DGR) as defined by Forsythe and Van Heukelem (1987) and instantaneous growth rate (G) for mantle length (ML) and body weight (BW) of red flying squid (Ommastrephes bartramii) by sex and age class. Squid were collected in the North Pacific Ocean from July through November 2011.

\begin{tabular}{|c|c|c|c|c|c|c|c|c|}
\hline \multirow[b]{2}{*}{ Sex } & \multirow[b]{2}{*}{$\begin{array}{c}\text { Age } \\
\text { class }(d)\end{array}$} & \multirow[b]{2}{*}{$\begin{array}{c}\text { Sample } \\
\text { size }\end{array}$} & \multicolumn{3}{|c|}{ Mantle length } & \multicolumn{3}{|c|}{ Body weight } \\
\hline & & & $\begin{array}{c}\text { Mean } \\
\text { ML (mm) }\end{array}$ & $\begin{array}{c}\text { DGR } \\
(\mathrm{mm} / \mathrm{d})\end{array}$ & $\mathrm{G}$ & $\begin{array}{c}\text { Mean } \\
\text { BW (g) }\end{array}$ & $\begin{array}{r}\text { DGR } \\
(\mathrm{g} / \mathrm{d})\end{array}$ & $\mathrm{G}$ \\
\hline \multirow[t]{5}{*}{ Female } & $>150$ & 23 & 219.13 & - & - & 302.42 & - & - \\
\hline & $151-200$ & 34 & 241.74 & 0.45 & 0.20 & 374.67 & 1.44 & 0.43 \\
\hline & $201-250$ & 20 & 277.67 & 0.72 & 0.28 & 619.55 & 4.90 & 1.01 \\
\hline & $251-300$ & 26 & 321.27 & 0.87 & 0.29 & 1005.18 & 7.71 & 0.97 \\
\hline & $301-350$ & 4 & 374.75 & 1.07 & 0.31 & 1571.85 & 11.33 & 0.89 \\
\hline \multirow[t]{5}{*}{ Male } & $>150$ & 32 & 216.88 & - & - & 287.76 & - & - \\
\hline & $151-200$ & 38 & 241.16 & 0.49 & 0.21 & 399.54 & 2.24 & 0.66 \\
\hline & $201-250$ & 23 & 277.22 & 0.72 & 0.27 & 613.65 & 4.28 & 0.86 \\
\hline & $251-300$ & 7 & 318.71 & 0.83 & 0.28 & 959.06 & 6.91 & 0.89 \\
\hline & $301-350$ & 1 & 354.00 & 0.71 & 0.21 & 1440.30 & 9.62 & 0.81 \\
\hline
\end{tabular}




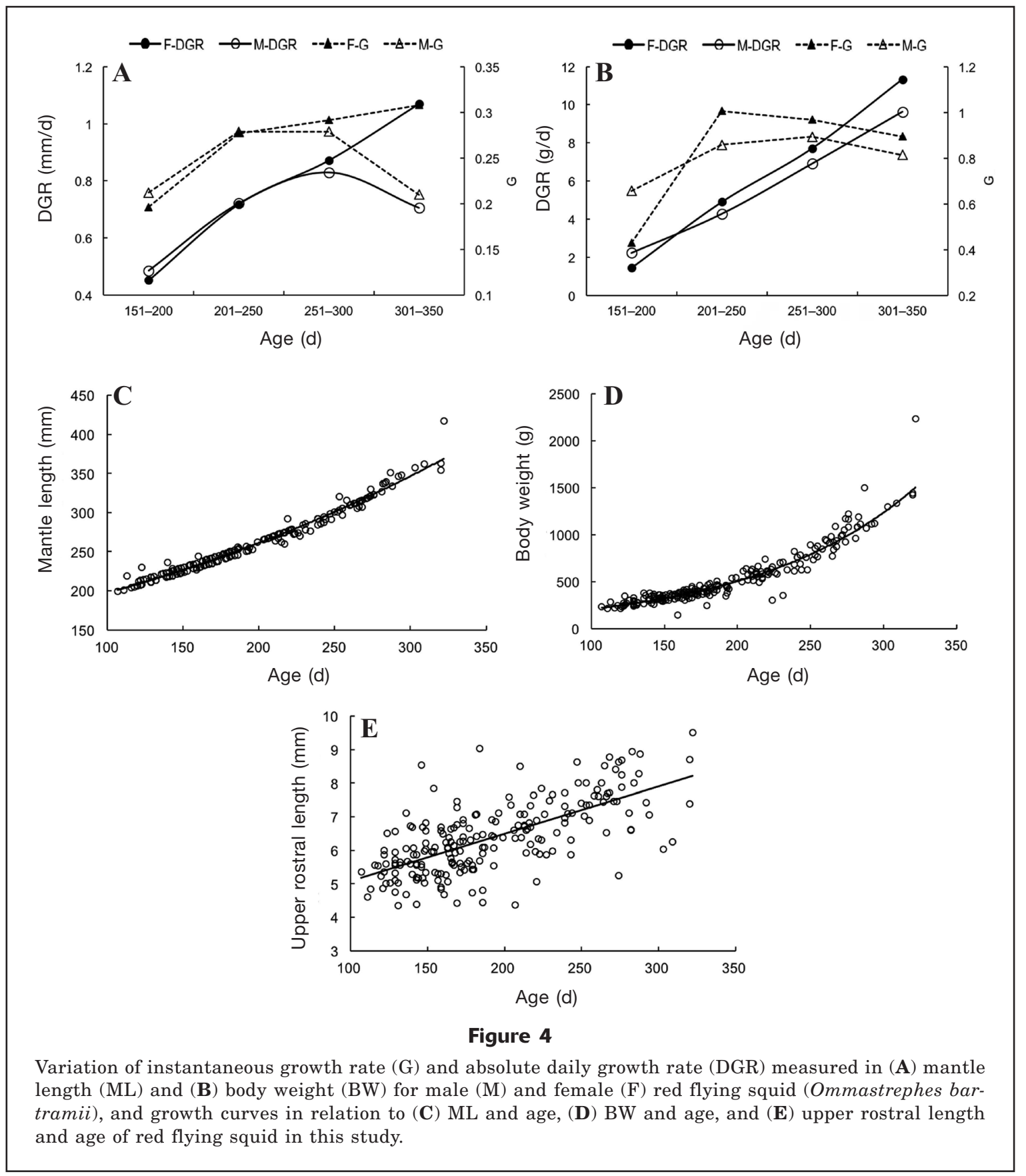

ranged from 150 to $250 \mathrm{~g}$. The $\mathrm{BW}$ of males ranged from 210 to $1440 \mathrm{~g}$ (average $=462 \mathrm{~g}$ [SD 225]); $92.7 \%$ of males ranged from 150 to $250 \mathrm{~g}$ (Fig. 3B).

The estimated age, which was based on the microstructure of upper beak RSS, ranged from 107 to 322 $\mathrm{d}$ (mean age=203 d [SD 55]) for females. The dominant age for females ranged from 150 to $300 \mathrm{~d}$-a range that accounted for $75.4 \%$ of the female samples. Estimated age ranged from 110 to $320 \mathrm{~d}$ ( mean age $=180 \mathrm{~d}$ [SD 45]) for males, and the dominant age, from 110 to 250 $\mathrm{d}$, which accounted for $92.2 \%$ of male samples (Fig. $3 \mathrm{C}$ ). The back-calculated hatching time in this study ranged from October 2010 through June 2011. The peak hatching time occurred from January through April for females, accounting for $72.7 \%$ of female samples, and from February through April for males, accounting for $74.7 \%$ of male samples (Fig. 3D). Most of the squid in this study hatched in late winter and early spring.

\section{Growth rate patterns}

Growth rate patterns were similar between $\mathrm{ML}$ and BW despite squid age (Table 1; Fig. 4, A and B). For female squids, the maximum DGR was $1.07 \mathrm{~mm} / \mathrm{d}$ for 


\section{Table 2}

Results from an analysis of covariance between sexes of red flying squid (Ommastrephes bartramii) in the relationships between age and the following variables: mantle length (ML), body weight (BW), and upper rostral length (URL). No differences between sexes were significant.

\begin{tabular}{lccc}
\hline Measurements & $\mathrm{df}$ & $F$ & $P$ \\
\hline ML & 107 & 0.125 & 0.725 \\
BW & 199 & 0.065 & 0.806 \\
URL & 151 & 1.974 & 0.166
\end{tabular}

ML and $11.33 \mathrm{~g} / \mathrm{d}$ for BW within 301-350 d (Table 1; Fig. 4, A and B), and the maximum $\mathrm{G}$ was 0.31 for ML within 301-350 d and 0.97 for BW within 251-300 d. In males, maximum DGR occurred within 251-300 d for ML (0.83 mm/d) and then decreased, and maximum $\mathrm{G}$ also occurred during within 251-300 $\mathrm{d}$ for both ML (0.28) and BW (0.89) (Table 1, Fig. 4, $\mathrm{A}$ and $\mathrm{B}$ ).

On the basis of results of the ANCOVA test, there was no significant difference in $\mathrm{ML}, \mathrm{BW}$, and URL between females and males $(P>0.05)$ (Table 2$)$. Therefore, we used the pooled data to analyze the relationship between ML, BW, URL, and age. Growth curves of ML-age and BW-age relationships were fitted with an exponential model, and the URL-age relationship provided the best fit with a linear model (Fig. 4, C-E) because it represented the best fit to the data (Table 3). These relationships were calculated with the following equations:

ML-age relationship: $M L=148.47 e^{0.0028 \text { age }}$ (coefficient of determination $\left.\left[r^{2}\right]=0.980, n=211, P<0.01\right)$

$\mathrm{BW}$-age relationship: $\mathrm{BW}=83.80 e^{0.009 \text { age }}\left(r^{2}=0.914\right.$, $n=211, P<0.01$ )

URL-age relationship: $U R L=0.0141$ age +3.6816 $\left(r^{2}=0.460, n=211, P<0.01\right)$

\section{Discussion}

The beak has been used to estimate age for a few neritic molluscan species (e.g., the common octopus, Perales-Raya et al., 2014; Octopus maya, Bárcenas et al., 2014). On the basis of the results of our study, we can see that the microstructure of the beak in red flying squid is similar to that in different cephalopods, as was reported in a previous study (Perales-Raya et al., 2010). Although the rostrum in squids seems to account for a much larger proportion of the crest than it does in octopuses, RSS increments are smaller in squid than in octopuses, nearly $12 \mu \mathrm{m}$ in this study compared with roughly $20 \mu \mathrm{m}$ for common octopus (Raya and Hernández-González, 1998) and with 15-30 $\mu \mathrm{m}$ after 50 increments reported by Perales-Raya et al. (2010). In this study, we used only reflected light to observe the increments clearly, as opposed to the use of violet or ultraviolet light by Perales-Raya et al. (2010). It is easy to distinguish RSS increments at low magnification with reflected light, but this method should be used with caution because it is easy to confuse "first-order" and "second-order" increments, as it is with statoliths (Arkhipkin and Shcherbich, 2012). Check rings were also found in this study, and those rings may have resulted from stressful conditions, such as spawning (Perales-Raya et al., 2014). The microstructure of statoliths also displays check rings (Chen et al., 2013).

This study is one of the first that has provided estimated ages for oceanic species of ommasterphid squid on the basis of beak microstructure. Cephalopods are typically short-lived invertebrates, and the lifespan of red flying squid was estimated to average about 1 year in previous reports (Bigelow and Landgraph, 1993; Yatsu et al., 1997; Chen and Chiu, 2003; Chen et al., 2011). All the squid analyzed in this study were less than 1 year in age, and the results of this study are consistent with the results of previous studies where ages were 


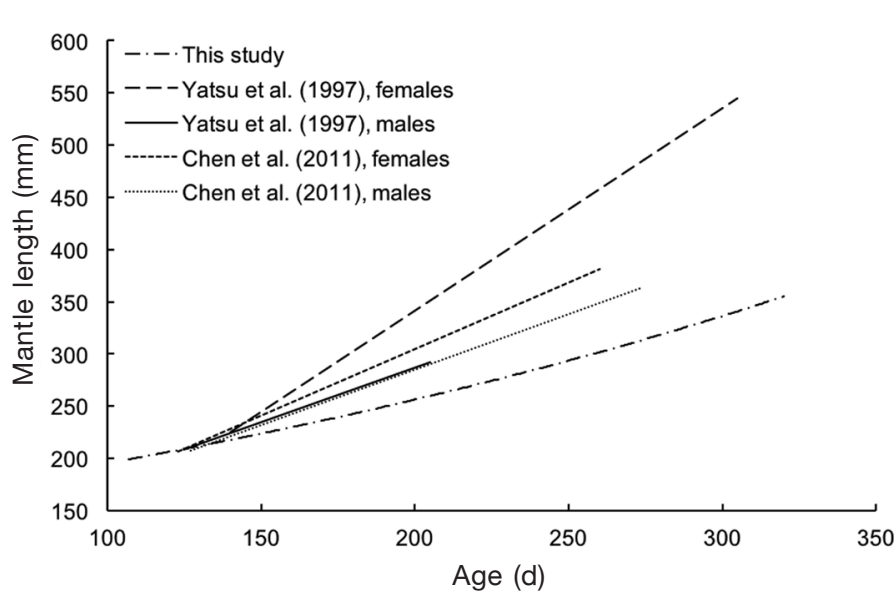

Figure 5

Comparison of growth curves in relation to mantle length (ML) and age for red flying squid (Ommastrephes bartramii) from different studies of the age and growth of this species. similar to that of males that can be described best with a Gompertz function, but large-size females in the northwestern stock grew much faster than males in either stock. Therefore, the female samples in our study may belong to the small-size group of females in the northwestern stock-a possibility that could explain the nearly synchronous growth between sexes. It is also notable that the ML DGR for males was much lower than that for females after ages 301-350 d (Fig. 4). The reason for this difference may be the greater energy need of females to support their metabolism during gametogenesis (Rocha et al., 2001).

There was no significant difference in growth curves between the 2 sexes, according to the results of ANCOVA $(P>0.05)$. Exponential curves seem to be appropriate for $\mathrm{ML}-$ age and $\mathrm{BW}-$ age relationships, whereas a linear curve was suitable for the URL-age relationship, although it showed a low correlation between the two variables. Different relationships between age and $\mathrm{ML}$ and $\mathrm{BW}$ have been found with various techniques in previous estimated from statolith growth increments (Yatsu et al., 1997; Yatsu, 2000).

In a previous study, hatching time was estimated to be from January through April, indicating that samples belonged to the winter-spring cohort (Chen and Chiu, 2003). The winter-spring cohort inhabits traditional fishing grounds $\left(150^{\circ}\right.$ to $\left.170^{\circ} \mathrm{E}\right)$ in the Northwest $\mathrm{Pa}$ cific (Bower and Ichii, 2005). We obtained results for hatching time, using a back-calculation based on upper beak increments, and our results were similar to estimates from statoliths for squid caught in a similar area and time during a previous study (Chen et al., 2011). Meanwhile, age were validated for the same species by using statoliths and beaks (Liu et al., 2015). The results from that previous study showed that beak increments had a high correlation with statolith increments for red flying squid: beak increments $=1.0177 \times \mathrm{s}-$ tatolith increments $-6.6795\left(r^{2}=0.969, n=21, P<0.001\right)$ (Liu et al., 2015). Therefore, we conclude that the beak is a hard structure that can be used reliably for age determination of ommasterphid species.

Females and males presented a similar growth pattern during ontogenesis (Table 1, Fig. 4). This finding differs from the observation of Chen et al. (2011), who suggested that females grow faster than males in every age class and that the peak growth rates occur in a relatively younger age class (140-220 d) (Chen et al., 2011). Sexual asynchrony of growth for red flying squid at different life stages also was found by Yatsu et al. (1997) and Brunetti et al. (2006). Chen and Chiu (2003) analyzed the growth of 2 geographically distinct stocks of red flying squid in the North Pacific Ocean and divided the females into 2 groups: large-size (>350 $\mathrm{mm} \mathrm{ML)}$ and small-size $(<350 \mathrm{~mm}$ ML) females. They found that small-size females in the northwestern stock had a growth mode that was studies (e.g., exponential model for paralarve, Bigelow and Landgraph, 1993; Yatsu, 2000; linear model, Yatsu et al., 1997, Chen et al., 2011; Gompertz model, Chen and Chiu, 2003). The exponential curve is a logical choice for describing the very fast growth rate of squid, especially for paralarve (Bigelow and Landgraph, 1993; Sakai et al., 1999, 2006; Yatsu, 2000).

We also compared the growth curves for adult red flying squid with those derived from 2 other studies, and we found that our reported growth rate was relatively lower than those rates in the other 2 studies (Fig. 5). There are 2 potential reasons for this difference: 1) the female squids in this study belonged to the group of small-size females in the northwestern stock (Chen and Chiu, 2003), a group that tends to have a low growth rate than that of the squid used in the other 2 studies, especially in the study by Yatsu et al. (1997), whose samples may have belonged to large-size females of that stock, and 2) the size and life span of squid can be influenced by ambient temperature, an influence that is more obvious in extreme weather (e.g., El Ninõ or La Ninã), as has been documented for the jumbo squid (Dosidicus gigas) (Arkhipkin et al., 2015).

Compared with squid in our 2011 study, squid in previous studies tended to attain larger sizes but have a shorter life span (in years) with warm temperatures (i.e., squid hatched during 1991-1993 for Yatsu's [2000] study and in 1997 for Chen and Chiu's [2003] study) and to attain smaller sizes but a long life span with cold temperatures (i.e., squid hatched in 2007 for the Chen et al. [2011] study). However, model selection can be influenced by sample size and sampling range. Additional sampling and a greater size range of individuals will be needed to evaluate growth functions more thoroughly. 


\section{Acknowledgments}

The support of those scientists on scientific surveys conducted with 2 commercial jigging vessels, FV Jinhai 827 and FV Ningtai 21 is gratefully acknowledged. This work was funded by the National Science Foundation of China (NSFC41306127 and NSFC41276156), National Science Foundation of Shanghai (13ZR1419700), the Innovation Program of Shanghai Municipal Education Commission (13YZ091), State 863 projects (2012AA092303), the Funding Program for Outstanding Dissertations in Shanghai Ocean University, the Funding Scheme for Training Young Teachers in Shanghai Colleges and Shanghai Leading Academic Discipline Project (Fisheries Discipline). The involvement of Y. Chen was supported by SHOU International Center for Marine Studies and Shanghai 1000 Talent Program.

\section{Literature cited}

Arkhipkin, A. I., and Z. N. Shcherbich.

2012. Thirty years' progress in age determination of squid using statoliths. J. Mar. Biol. Assoc. U.K. 92: 1389-1398. Article

Arkhipkin, A., J. Argüelles, Z. Shcherbich, and C. Yamashiro.

2015. Ambient temperature influences adult size and life span in jumbo squid (Dosidicus gigas). Can. J. Fish. Aquat. Sci. 72:400-409. Article

Bárcenas, G. V., C. Perales-Raya, A. Bartolomé, E. Almansa, and C. Rosas.

2014. Age validation in Octopus maya (Voss and Solís, 1966) by counting increments in the beak rostrum sagittal sections of known age individuals. Fish. Res. 152:93-97. Article

Bigelow, K. A., and K. C. Landgraph.

1993. Hatch dates and growth of Ommastrephes bartramii paralarvae from Hawaiian waters as determined from statolith analysis. In Recent advances in cephalopod fisheries biology (T. Okutani, R. K. O'Dor, and T. Kubodera, eds.), p. 15-24. Tokai Univ. Press, Tokyo.

Bower, J. R., and T. Ichii.

2005. The red flying squid (Ommastrephes bartramii): a review of recent research and the fishery in Japan. Fish. Res. 76:39-55. Article

Brunetti, N. E., M. L. Ivanovic, A. Aubone, and L. N. Pascual. 2006. Reproductive biology of red squid (Ommastrephes bartramii) in the Southwest Atlantic. Rev. Invest. Desarr. Pesq. 18:5-19.

Canali, E., G. Ponte, P. Belcari, F. Rocha, and G. Fiorito.

2011. Evaluating age in Octopus vulgaris: estimation, validation and seasonal differences. Mar. Ecol. Prog. Ser. 441:141-149. Article

Castanhari, G., and A. R. G. Tomás.

2012. Beak increment counts as a tool for growth studies of the common octopus Octopus vulgaris in southern Brazil. Bol. Inst. Pesca, São Paulo. 38:323-331.

Chen, C.-S.

2010. Abundance trends of two neon flying squid (Ommastrephes bartramii) stocks in the North Pacific. ICES J. Mar. Sci. 67:1336-1345. Article
Chen, C.-S., and T.-S. Chiu.

2003. Variations of life history parameters in two geographical groups of the neon flying squid, Ommastrephes bartramii, from the North Pacific. Fish. Res. 63:349-366. Article

Chen, X. J., X. H. Zhao, and Y. Chen.

2007. Influence of El Niño/La Niña on the western winter-spring cohort of neon flying squid (Ommastrephes bartramii) in the northwestern Pacific Ocean. ICES J. Mar. Sci. 64:1152-1160. Article

Chen, X.-J., J. Ma, B.-L. Liu, H.-J. Lu, and J. Cao.

2011. Population structure, age and growth of neon flying squid (Ommastrephes bartramii) in the northwest Pacific Ocean based on statolith microstructure. J. Fish. China 35:1191-1198. [In Chinese with English abstract.]

Chen, X., H. Lu, B. Liu, Y. Chen, S. Li, and M. Jin.

2012. Species identification of Ommastrephes bartramii, Dosidicus gigas, Sthenoteuthis oualaniensis and Illex rgentines (Ommastrephidae) using beak morphological variables. Sci. Mar. 76:473-481. Article

Chen, X., J. Li, B. Liu, Y. Chen, G. Li, Z. Fang, and S. Tian. 2013. Age, growth and population structure of jumbo flying squid, Dosidicus gigas, off the Costa Rica Dome. J. Mar. Biol. Assoc. U.K. 93:567-573. Article

Cherel, Y., and K. A. Hobson.

2005. Stable isotopes, beaks and predators: a new tool to study the trophic ecology of cephalopods, including giant and colossal squids. Proc. R. Soc., B. 272:1601-1607. Article

Clarke, M. R.

1965. "Growth rings" in the beaks of the squid Moroteuthis ingens (Oegopsida: Onychoteuthidae). Malacologia 3:287-307.

Clarke, M. R. (ed.)

1986. A handbook for the identification of cephalopod beaks, 273 p. Clarendon Press, Oxford, UK.

Dawe, E. G., and Y. Natsukari.

1991. Light microscopy. In Squid age determination using statoliths. Proceedings of the International Workshop held in the Istituto di Tecnologia della Pesca e del Pescato (ITPP-CNR), Spec. Publ. 1; Mazara del Vallo, Italy, 9-14 October 1989 (P. Jereb, S. Ragonese, and S. Von Boletzky, eds.), p. 83-95. ITPP, Mazara del Vallo, Italy.

Durholtz, M. D., M. R. Lipinski, and J. G. Field.

2002. Laboratory validation of periodicity of incrementation in statoliths of the South African chokka squid Loligo vulgaris reynaudii (d'Orbigny, 1845): a reevaluation. J. Exp. Mar. Biol. Ecol. 279:41-59. Article

Forsythe J. W., and W. F. Van Heukelem.

1987. Growth. In Cephalopod life cycles. Volume II: comparative reviews (P. R. Boyle, ed.), p. 135-156. Academic Press, London.

Guerra, Á., A. B. Rodríguez-Navarro, Á. F. González, C. S. Romanek, P. Álvarez-Lloret, and G. J. Pierce.

2010. Life-history traits of the giant squid Architeuthis $d u x$ revealed from stable isotope signatures recorded in beaks. ICES J. Mar. Sci. 67:1425-1431. Article

Gröger, J., U. Piatkowski, and H. Heinemann.

2000. Beak length analysis of the Southern Ocean squid Psychroteuthis glacialis (Cephalopoda: Psychroteuthidae) and its use for size and biomass estimation. Polar Biol. 23:70-74. Article

Haddon, M.

2001. Modelling and quantitative methods in fisheries, 406 p. Chapman and Hall, London. 
Hernández-López, J. L., J. J. Castro-Hernández, and V. Hernández-García.

2001. Age determined from the daily deposition of concentric rings on common octopus (Octopus vulgaris) beaks. Fish. Bull. 99:679-684.

$\mathrm{Hu}, \mathrm{G}$., X. Chen, B. Liu, and Z. Fang.

2015. Microstructure of statolith and beak for Dosidicus gigas and its determination of growth increments. J. Fish. China 39:361-370. [In Chinese with English abstract.] Article

Ichii, T., K. Mahapatra, M. Sakai, D. Inagake, and Y. Okada. 2004. Differing body size between the autumn and the winter-spring cohorts of neon flying squid $(\mathrm{Om}$ mastrephes bartramii) related to the oceanographic regime in the North Pacific: a hypothesis. Fish. Ocean.13:295-309. Article

Ichii, T., K. Mahapatra, M. Sakai, and Y. Okada.

2009. Life history of the neon flying squid: effect of the oceanographic regime in the North Pacific Ocean. Mar. Ecol. Prog. Ser. 378:1-11. Article

Jackson, G. D., A. I. Arkhipkin, V. A. Bizikov, and R. T. Hanlon. 1993. Laboratory and field corroboration of age and growth from statoliths and gladii of the loliginid squid Sepioteuthis lessoniana (Mollusca: Cephalopoda). In Recent advances in cephalopod fisheries biology (T. Okutani, R. K. O’Dor, and T. Kubodera, eds.), p. 189-199. Tokai Univ. Press, Tokyo.

Jackson, G. D., N. G. Buxton, and M. J. A. George.

1997. Beak length analysis of Moroteuthis ingens (Cephalopoda: Onychoteuthidae) from the Falkland Islands region of the Patagonian Shelf. J. Mar. Biol. Assoc. U.K. 77:1235-1238. Article

Jereb, P., and C. F. E. Roper (eds.).

2010. Cephalopods of the world. An annotated and illustrated catalogue of cephalopod species known to date. Vol. 2. Myopsid and oegopsid squids. FAO Species Catalogue for Fishery Purposes 4, 605 p. FAO, Rome.

Keyl, F.

2009. The cephalopod Dosidicus gigas of the Humboldt Current system under the impact of fishery and environmental variability. Ph.D. thesis, 214 p. Univ. Bremen, Bremen, Germany.

Lipinski, M.

1986. Methods for the validation of squid age from statoliths. J. Mar. Biol. Assoc. U.K. 66:505-526. Article

Liu, B. L., X. J. Chen, Y. Chen, and G. Y. Hu.

2015. Determination of squid age using upper beak rostrum sections: technique improvement and comparison with the statolith. Mar. Biol. 162:1685-1693. Article

Markaida, U., C. Quiñónez-Velázquez, and O. Sosa-Nishizaki.

2004. Age, growth and maturation of jumbo squid Dosidicus gigas (Cephalopoda: Ommastrephidae) from the Gulf of California, Mexico. Fish. Res. 66:31-47. Article

Martínez, P., A. Sanjuan, and A. Guerra.

2002. Identification of Illex coindetii, I. illecebrosus and I. rgentines (Cephalopoda: Ommastrephidae) throughout the Atlantic Ocean; by body and beak characters. Mar. Biol. 141:131-143. Article

Moltschaniwskyj, N., and M. Cappo.

2009. Alternatives to sectioned otoliths: the use of other structures and chemical techniques to estimate age and growth for marine vertebrates and invertebrates. In Tropical fish otoliths: information for assessment, management and ecology (B. S. Green, B. D. Mapstone, G.
Carlos, and G. A. Begg, eds.) p. 133-173. Springer Netherlands, Heidelberg, Germany.

Navarro, J., M. Coll, C. J. Somes, and R. J. Olson.

2013. Trophic niche of squids: insights from isotopic data in marine systems worldwide. Deep Sea Res. (II. Top. Stud. Oceanogr.) 95:93-102. Article

Nishikawa, H., H. Igarashi, Y. Ishikawa, M. Sakai, Y. Kato, M. Ebina, N. Usui, M. Kamachi, and T. Awaji.

2014. Impact of paralarvae and juveniles feeding environment on the neon flying squid (Ommastrephes bartramii) winter-spring cohort stock. Fish. Ocean. 23:289-303. Article

Nixon, M.

1973. Beak and radula growth in Octopus vulgaris. J. Zool. 170:451-462. Article

Perales-Raya, C., A. Bartolomé, M. T. García-Santamaría, P. Pascual-Alayón, and E. Almansa.

2010. Age estimation obtained from analysis of octopus (Octop us vulgaris Cuvier, 1797) beaks: improvements and comparisons. Fish. Res. 106:171-176. Article

Perales-Raya, C., A. Jurado-Ruzafa, A. Bartolomé, V. Duque, M. N. Carrasco, and E. Fraile-Nuez.

2014. Age of spent Octopus vulgaris and stress mark analysis using beaks of wild individuals. Hydrobiologia 725:105-114. Article

Raya, C. P., and C. L. Hernández-González.

1998. Growth lines within the beak microstructure of the octopus Octopus vulgaris Cuvier, 1797. S. Afr. J. Mar. Sci. 20:135-142. Article

Rocha, F., A. Guerra, and A. F. González.

2001. A review of reproductive strategies in cephalopods. Biol. Rev. Camb. Philos. Soc., 76:291-304. Article

Rodríguez-Domínguez, A., C. Rosas, I. Méndez-Loeza, and U. Markaida.

2013. Validation of growth increments in stylets, beaks and lenses as ageing tools in Octopus maya. J. Exp. Mar. Biol. Ecol. 449:194-199. Article

Sakai, M., N. E. Brunetti, M. Ivanovic, and B. Elena.

1999. Validation of daily increments of Illex argentines statolith. In Advances in methods and technology applied to fisheries research. Final seminar of INIDEPJICA Project on assessment and monitoring of fisheries resources 1994-1999, p. 95-97. Instituto Nacional de Investigación y Desarrollo Pesquero (INIDEP), Mar del Plata, Argentina.

Sakai, M., N. Brunetti, J. Bower, B. Elena, T. Goto, T. Ichii, M. Ivanovic, Y. Sakurai, T. Wakabayashi and A. Yatsu.

2006. Upper-beak growth increments in ommastrephid paralarvae. In Cephalopod life cycles: Cephalopod International Advisory Council Symposium 2006 (CIAC '06); Hobart, Tasmania, Australia, 6-10 February, p. 54. Univ. Tasmania, Hobart, Australia. [Abstract]

Semmens, J. M., G. T. Pecl, B. M. Gillanders, C. M. Waluda, E. K. Shea, D. Jouffre, T. Ichii, K. Zumholz, O. N. Katugin, S. C. Leporati, and P. W. Shaw.

2007. Approaches to resolving cephalopod movement and migration patterns. Rev. Fish Biol. Fish. 17:401-423. Article

Spratt, J. D.

1978. Age and growth of the market squid, Loligo opalescens Berry, in Monterey Bay. Calif. Dep. Fish Game, Fish Bull. 169:35-44. 
Watanabe, H., T. Kubodera, T. Ichii, and S. Kawahara.

2004. Feeding habits of neon flying squid Ommastrephes bartramii in the transitional region of the central North Pacific. Mar. Ecol. Prog. Ser. 266:173-184. Article

Yatsu, A., S. Midorikawa, T. Shimada, and Y. Uozumi. 1997. Age and growth of the neon flying squid, Ommastrephes bartrami, in the North Pacific Ocean. Fish. Res. 29:257-270. Article

Yatsu, A.

2000. Age estimation of four oceanic squids, Ommas- trephes bartramii, Dosidicus gigas, Sthenoteuthis oualaniensis, and Illex rgentines (Cephalopoda, Ommastrephidae) based on statolith microstructure. Japan Agric. Res. Q. 34:75-80.

Yatsu, A., T. Watanabe, J. Mori, K. Nagasawa, Y. Ishida, T. Meguro, Y. Kamei, and Y. Sakurai.

2000. Interannual variability in stock abundance of the neon flying squid, Ommastrephes bartramii, in the North Pacific Ocean during 1979-1998: impact of driftnet fishing and oceanographic conditions. Fish. Ocean. 9:163-170. Article 